\title{
MATHEMATICS, LOVE, AND TATTOOS
}

\author{
EDWARD FRENKEL
}

The lights were dimmed... After a few long seconds of silence the movie theater went dark. Then the giant screen lit up, and black letters appeared on the white background:

\author{
Red Fave Productions \\ in association with Sycomore Films \\ with support of \\ Fondation Sciences Mathématiques de Paris \\ present

\section{Rites of Love and Math}

The 400-strong capacity crowd was watching intently. I'd seen it countless times in the editing studio, on my computer, on TV... But watching it for the first time on a panoramic screen was a special moment which brought up memories from the year before.

I was in Paris as the recipient of the first Chaire d'Excellence awarded by Fondation Sciences Mathématiques de Paris, invited to spend a year in Paris doing research and lecturing about it.

Paris is one of the world's centers of mathematics, but also a capital of cinema. Being there, I felt inspired to make a movie about math. In popular films, mathematicians are usually portrayed as weirdos and social misfits on the verge of mental illness, reinforcing the stereotype of mathematics as a boring and irrelevant subject, far removed from reality. Would young people want a career in math or science after watching these movies? I thought something had to be done to confront this stereotype.

Contribution to the Proceedings of the Symposium "Matematica e Cultura" 2012, Venice (ed. M. Emmer) to be published by Springer Verlag.

Parts of the article are borrowed from my book Love and Math, which will be published by Basic Books in the Fall of 2013.

For more information about the film, visit $\frac{\mathrm{http}: / / \text { ritesofloveandmath.com. }}{1}$ 
My friend, mathematician Pierre Schapira, introduced me to a young talented film director, Reine Graves. A former fashion model, she had previously directed several original, bold short films (one of which won the Pasolini Prize at the Festival of Censored Films in Paris). At a lunch meeting arranged by Pierre, she and I hit it off right away. I suggested we work together on a film about math, and she liked the idea. Months later, asked about this, she said that she felt mathematics was one of the last remaining areas where there was genuine passion.

As we started to brainstorm what our film would be about, I showed Reine a couple of photographs I had made, in which I painted tattoos of mathematical formulas on human bodies. We decided we would try to make a film involving the tattoo of a formula.

Tattoo, as an art form, originated in Japan. I had visited Japan a dozen times, was fascinated by the Japanese culture. We turned to the Japanese cinema for inspiration; in particular, to a film by the great Japanese writer Yukio Mishima Rite of Love and Death, based on his short story Yûkoku (or Patriotism). Mishima himself directed and starred in it.

This film made a profound impression on me. It was as though I was possessed by a powerful force.

Rite of Love and Death is black-and-white; it unfolds on the austere stylized stage of the Japanese Noh Theater. No dialogue, with music from Wagner's opera Tristan and Isolde playing in the background. There are two characters: a young officer of the Imperial Guard, Lieutenant Takeyama, and his wife, Reiko. The officer's friends stage an unsuccessful coup d'etat (here the film refers to actual events of February 1936, which Mishima thought had a dramatic effect on Japanese history). The Lieutenant is given the order to execute the perpetrators of the coup, which he cannot do - they are close friends. But neither can he disobey the order of the Emperor. The only way out is ritual suicide, seppuku (or harakiri). When he tells Reiko, she says she will follow him to the better world. After they make love, the Lieutenant commits seppuku (this is shown in graphic detail). Then Reiko kills herself by driving a knife in her throat... At the end of the film we see them both lying dead in final embrace on the beautifully groomed pebbles of a traditional Zen garden.

The 29 minutes of film touched me deeply. I could sense the vigor and clarity of Mishima's vision. His presentation was forceful, raw, unapologetic. You may disagree with his ideas (and in fact his vision of the intimate link between love and death does not appeal to me), but you have to respect the author for being so strong and uncompromising.

Mishima's film went against the usual conventions of cinema: it was silent, with written text between the "chapters" of the movie to explain what's going to happen next. It was theatrical; scenes carefully staged, with little movement. But I was captivated by the undercurrent of emotion underneath. (I did not know 
yet the details of Mishima's own death, its eerie resemblance to what happened in his film - and this was probably for the best.)

Perhaps, the film resonated with me so much in part because Reine and I were also trying to create an unconventional film, to talk about mathematics the way no one had talked about it before. I felt that Mishima had created the aesthetic framework and language that we were looking for.

I recount what happened next in my forthcoming book Love and Math. I called Reine and told her that we should make a film just like Mishima's. "But what will our film be about?" she asked. Suddenly, words started coming out of my mouth. Everything was crystal clear.

"A mathematician creates a formula of love," I said, "but then discovers the flip side of the formula: it can be used for Evil as well as for Good. He realizes he has to hide the formula to protect it from falling into the wrong hands. And he decides to tattoo it on the body of the woman he loves."

We decided to call our film Rites of Love and Math. We envisioned it as an allegory, showing that a mathematical formula can be beautiful like a poem, a painting, or a piece of music. The idea was to appeal not to the cerebral, but to the intuitive, visceral. Let the viewers feel rather than understand it first. We thought that this would make mathematics more human, inspire viewer's curiosity about it.

We also wanted to show the passion involved in mathematical research. People tend to think of mathematicians as sterile, cold. But the truth is that our work is full of passion and emotion. And the formulas you discover really do get under your skin - that was the intended meaning of the tattooing in the film.

In the film, the Mathematician discovers the "formula of love." Of course, this is a metaphor: We are always trying to reach for complete understanding, ultimate clarity, want to know everything. In the real world, we have to settle for partial knowledge and understanding. But what if someone were able to find the ultimate Truth; what if it could be expressed by a mathematical formula? This would be the "formula of love."

Such a formula, being so powerful, must also have a flip side: it could also be used for evil. This is a reference to the dangers of modern science. Think of a group of theoretical physicists trying to understand the structure of the atom. What they thought was pure scientific research inadvertently led them to the discovery of atomic energy. It brought us a lot of good, but also destruction and death. Likewise, a mathematical formula discovered as part of our quest for knowledge could potentially lead to disastrous consequences.

So our protagonist, the Mathematician, hides his formula by tattooing it on the body of the woman he loves. It's his gift of love, the product of his creation, passion, imagination. But who is she? In the framework of the mythical world we 
envisioned, she is the incarnation of Mathematics, Truth itself (hence her name Mariko, "truth" in Japanese; and that's why the word ISTINA, "truth" in Russian, is calligraphed on the painting hanging on the wall). The Mathematician's love for her is meant to represent his love for Mathematics and Truth, for which he sacrifices himself. But she survives and carries his formula, as she would their child. The Truth is eternal.

As Reine and I were getting more excited about our project, so did people around us. Soon, a crew of about 30 people was working on the film. Raphaël Fernandez, a talented musician, composed original music. We ordered a kimono and a painting. An artist was working on the decor. The film was taking life of its own.

The shooting took three days, in July of 2009. Those were some of the most exciting, and exhausting, days of my life. I wore several hats: co-director (with Reine), producer, actor... All of this was new to me, and I was learning on the job. It was an amazing journey, a wonderful collaboration with Reine and other filmmakers and artists helping us to fulfill our dream.

The central scene of the movie is the making of the tattoo. We shot it on the last day. Since I never had a tattoo, I had to learn about the process. These days tattoos are made with a machine, which would be an anachronism on the stage of Noh theater. In the past, tattoos were engraved with a bamboo stick - a longer, more painful process. I've been told it's still possible to find tattoo parlors in Japan which use this old technique. This is how we presented it in the film.

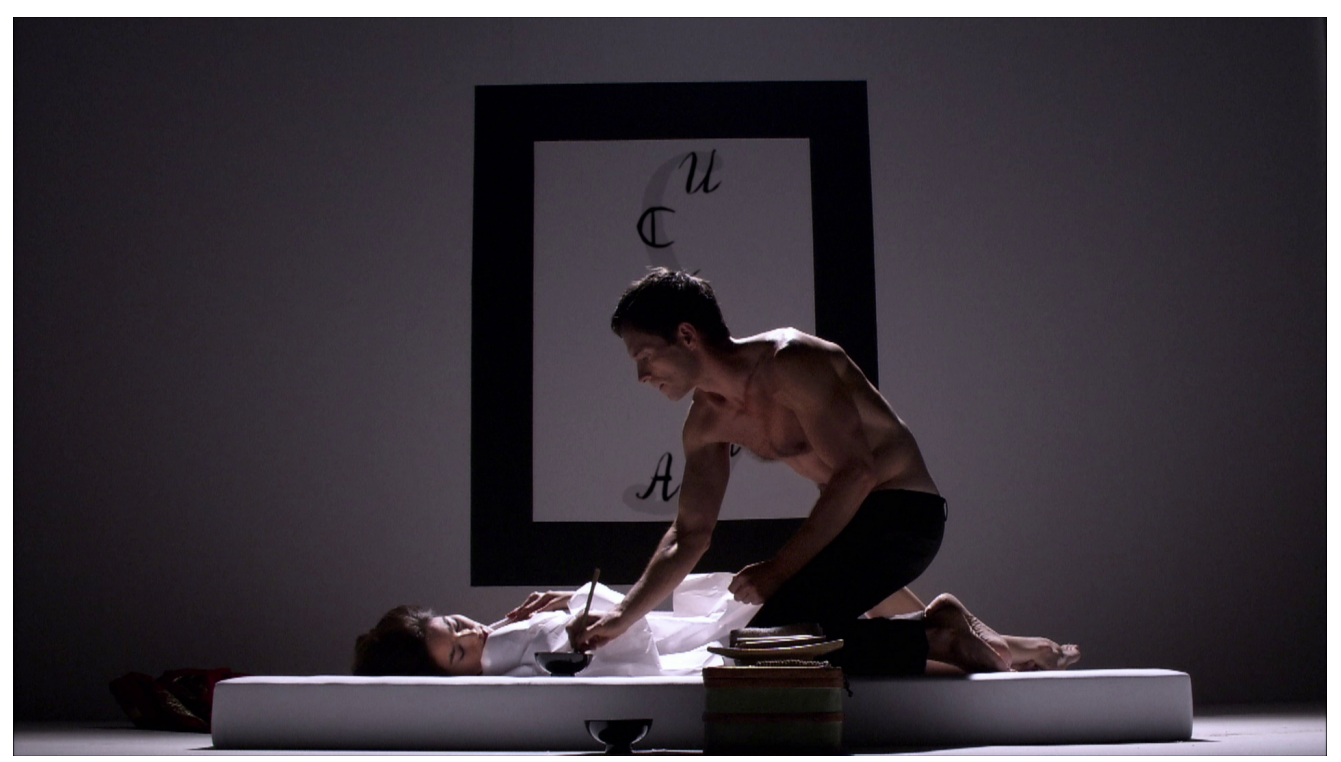


Oriane Giraud, our special effects artist, asked me a few days before the shooting to give her the formula that would be tattooed, so she could create the blueprint. Which formula should play the role of "formula of love"? A big question! It had to be sufficiently complicated (it's a formula of love, after all), aesthetically pleasing. We wanted to convey that a mathematical formula could be beautiful in content as well as form. And I wanted it to be $m y$ formula.

Doing "casting" for the formula of love, I stumbled on this:

$$
\begin{aligned}
\int_{\mathbb{P}^{1}} \omega F(q z, \overline{q z}) & =\left.\sum_{m, \bar{m}=0}^{\infty} \int_{|z|<\epsilon^{-1}} \omega_{z \bar{z}} z^{m} \bar{z}^{\bar{m}} d z d \bar{z} \cdot \frac{q^{m} \bar{q}^{\bar{m}}}{m ! \bar{m} !} \partial_{z}^{m} \partial_{\bar{z}}^{\bar{m}} F\right|_{z=0} \\
& +\left.q \bar{q} \sum_{m, \bar{m}=0}^{\infty} \frac{q^{m} \bar{q}^{\bar{m}}}{m ! \bar{m} !} \partial_{w}^{m} \partial_{\bar{w}}^{\bar{m}} \omega_{w \bar{w}}\right|_{w=0} \cdot \int_{|w|<q^{-1} \epsilon^{-1}} F w^{m} \bar{w}^{\bar{m}} d w d \bar{w}
\end{aligned}
$$

It appears as formula (5.7) in a 100-page paper [1], Instantons Beyond Topological Theory I, which I wrote with my two good friends, Andrey Losev and Nikita Nekrasov, in 2006.1

When we show the film, people always ask: What does this formula mean? Which is exactly what we were hoping for. If we had made a film in which I wrote this formula on a backboard and tried to explain its meaning, how many people would care for it? But seeing it in the form of a tattoo elicited a totally different reaction. It really got under everyone's skin.

So what does it mean? This work was the first installment in a series of papers we wrote about a new approach to quantum field theories with "instantons" special solutions of the theory minimizing the "action." Quantum field theory is a mathematical formalism for describing the behavior and interaction of elementary particles. Though it has been successful in accurately predicting a wide range of phenomena, there are many fundamental issues that are still poorly understood. Let me recall that all atoms consists of protons, neutrons, and electrons. Protons and neutrons, in turn, consist of smaller particles, called quarks. And those quarks are confined there - they cannot be separated. A proper theoretical explanation of this phenomenon is still lacking.

In the conventional (so-called, perturbative) approach to quantum field theory the starting point is the so-called "free theory" describing idealized noninteracting particles. Then we "turn on" the interaction between them. The problem is that in this approach the contribution of each instanton appears to be negligible, even though altogether they may "conspire" to create a powerful

\footnotetext{
${ }^{1}$ In the version published in Journal de l'Institut de Mathématiques de Jussieu, there is a footnote explaining that it played the role of "formula of love" in Rites of Love and Math.
} 
effect. Many physicists believe that the difficulties of the conventional formalism with taking the instantons into account could be the reason we don't have a satisfactory explanation of the confinement of quarks and other similar effects.

In our paper, we proposed a new approach, in which the starting point is not a free theory, but an idealized interacting theory in which the instantons are present from the beginning. The advantage of out theory is that the main quantities - the so-called "correlations functions" - are expressed by finite-dimensional integrals (in contrast to the conventional formalism, in which the integrals are infinitedimensional and hence poorly defined). Therefore, our theory is in principle completely solvable.

The above formula expresses the identity between two ways to compute correlation functions in our theory. We discovered it when we were working on this project three years earlier, in April of 2006, also in Paris.

Our world is four-dimensional (if we include both space and time dimensions), but four-dimensional theories are very complex. To simplify matters, we looked at the analogous two-dimensional, and then one-dimensional, models. That is to say, there is only time dimension. Such models, commonly referred to as "quantum mechanics," describe a single particle moving in a particular space (which could be of any dimension). Despite the simplifications, these one-dimensional models possess the salient features of the more realistic, four-dimensional, models. That's why it is useful to study them.

We considered the theory in which a particle was moving on the sphere, also known in mathematics as the "complex projective line," denoted $\mathbb{P}^{1}$ ( $\mathbb{P}$ stands for "projective," and 1 for one-dimensional, as a complex manifold). You can see this notation under the integral sign on the left hand side of the formula.

We wanted to compute the simplest correlation function in this theory, involving two "observables," denoted by $F$ and $\omega$ in our formula. On the one hand, the answer is given by an integral over the sphere; this is the left hand side of the formula. On the other hand, in our new theory we were getting a different answer: a sum over the "intermediate states," appearing on the right hand side. This answer is surprising, and so is the equality between the two expressions. If our new approach were correct, the two sides would have to be equal to each other. And indeed they are.

In other words, our formula says that two ways of computing the correlation functions - the old and the new - give the same answer. Little did we know at the time we discovered it that it would soon be slated to play the role of formula of love.

Oriane liked the formula, but said it was too involved for a tattoo. Could I simplify it? I slighly changed the notation, and here's how it appears in our film: 


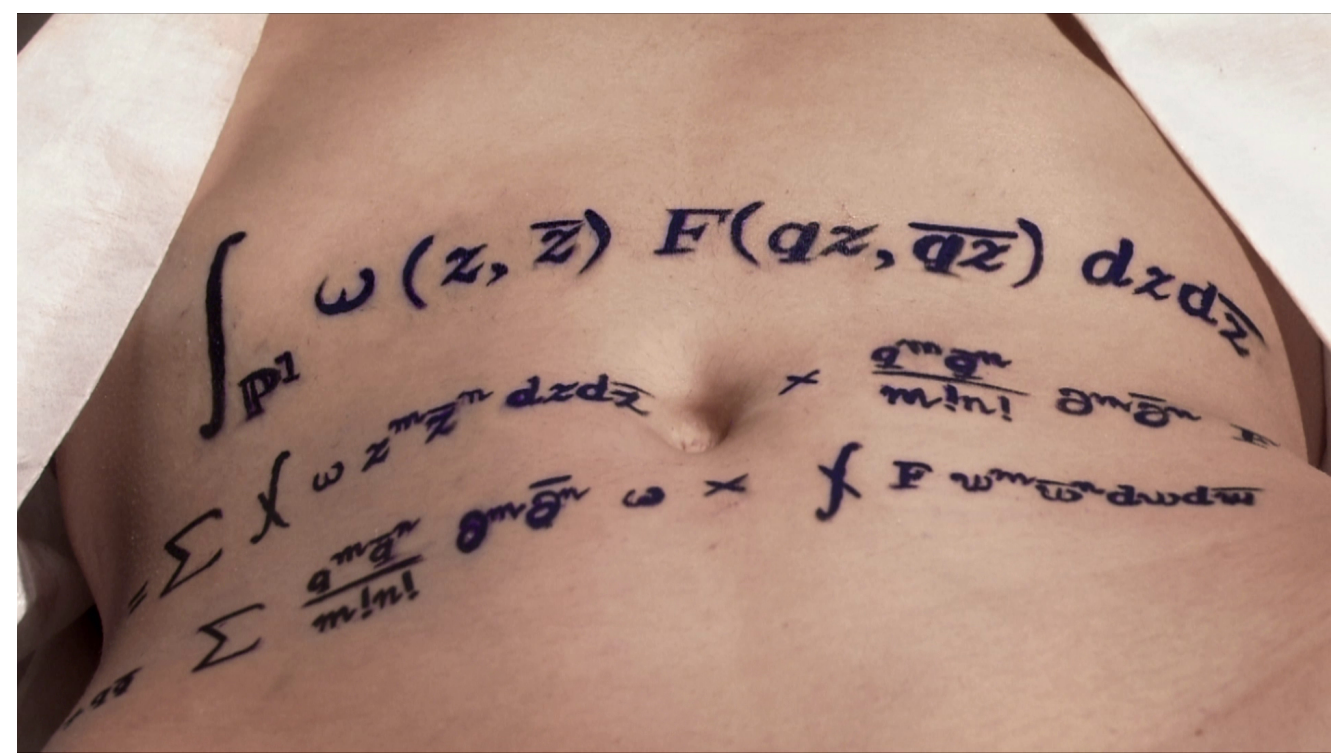

The work on the tattoo scene took us many hours. It was psychologically and physically draining both for me and for Kayshonne Insixieng May, the actress playing Mariko. We finished shooting close to midnight. It was an emotional moment for all of us on the set, after everything we had been through together.

Two months of post-production followed, at Sycomore Films, a French production company, with our multi-talented editor Thomas Bertay and visual effects magician Pierre Borde. And finally, the film finished, it was time to organize the premiere. Folks from Fondation Sciences Mathématiques de Paris, which generously supported our film, agreed to sponsor the premiere. We picked a wonderful venue: Max Linder Panorama. An old movie theater with a huge screen and modern video and sound systems, it is one of best theaters in Paris.

The crowd that gathered at the theater on April 14, 2010 was diverse: mathematicians, artists, filmmakers... Most of our crew was there, including Reine, Kayshonne, and our Director of Photography extraordinaire Daniel Barrau. On the big screen the picture was sharp and crisp, the colors vivid (the decision to use the most expensive Sony camera had paid off).

The first articles about the film started to appear. Le Monde called Rites of Love and Math "a stunning short film" that "offers an unusual romantic vision of mathematicians." And the New Scientist wrote:

It is beautiful to look at... If Frenkel's goal was to bring more people to maths, he can congratulate himself on a job well done. The formula of love, which is actually a simplified version of an equation he published in a 2006 paper on quantum field theory entitled "Instantons beyond topological theory I", will probably soon have 
been seen - if not understood - by a far larger audience than it would otherwise ever have reached.

Since then, the film has been shown at international film festivals in France, Spain, and in Berkeley, California. There have been more showings in Paris, Kyoto, Madrid, Santa Barbara, Bilbao, Venice... The screenings and the ensuing publicity gave me the opportunity to meet many people and hear different opinions. At first, this came as culture shock. Some of my mathematical works can be fully understood only by a small number of people; sometimes, no more than a dozen in the whole world at first. This was a film intended for a wide audience: hundreds were being exposed to it. And of course, they all interpreted it in their own ways.

In mathematics there is only one truth, and only one path to reach that truth. My mathematical work is perceived and interpreted in essentially the same way by everybody who reads it. Not so in cinema and in the arts in general. First, there isn't a single truth, and second, there are so many different paths to express the truth. And the viewer is always part of an artistic project: at the end of the day, it's all in the eye of the beholder. I have no influence over their perception. Coming to terms with this was a challenge to me, but gradually I came to embrace it. We get enriched when others share their views and insights. What matters the most for a work of art is that it touches people in some way, does not leave them indifferent.

When we show the film, people invariably ask: "Do you know the formula of love?" My response: "Every formula we create is a formula of love." Doing mathematics is a creative pursuit that requires passion, just like painting, music, and poetry. In order to discover something new and eternal about the world, you have to be in love with what you do. 


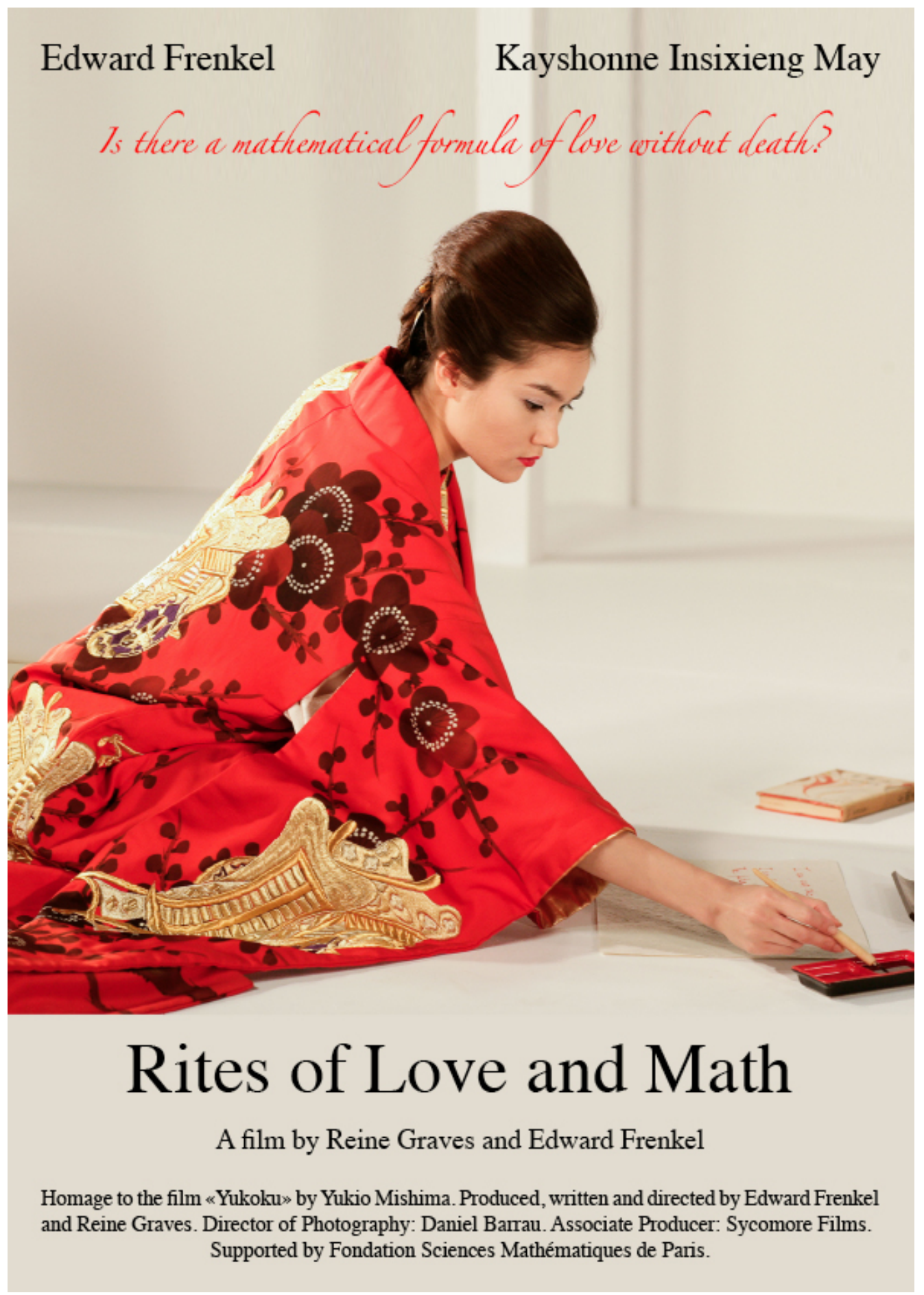

Film poster 


\section{Film CREDits}

Rites of Love and Math, 2010. 26 minutes, in color.

Written, produced, and directed by Edward Frenkel and Reine Graves.

Associate Producer Sycomore Films.

Cinematography by Daniel Barrau.

Music by Richard Wagner and Raphaël Fernandez.

With Edward Frenkel and Kayshonne Insixieng May.

More information: http://ritesofloveandmath.com

Rite of Love and Death (Y îkoku), 1965. 29 minutes, in black-and-white.

Written, produced, and directed by Yukio Mishima.

Associate producer Haraoki Fujii.

Associate director Masaki Domoto.

Cinematography by Kimio Watanabe.

Music by Richard Wagner.

With Yukio Mishima and Yushiko Tsuruoka.

\section{ACKNOWLEDGMents}

I thank Michele Emmer for the invitation to show our film at the annual Symposium "Matematica e Cultura" in Venice and to contribute to the Symposium Proceedings. I am grateful to Thomas Farber for his comments on a draft of this article.

\section{REFERENCES}

[1] E. Frenkel, A. Losev, and N. Nekrasov, Instantons beyond topological theory I, J. of Inst. Math. Jussieu 10 (2011) 463-565 (hep-th/0610149).

Department of Mathematics, University of California, Berkeley, CA 94720, USA 